\title{
Impaired cornea wound healing in a tenascin C-deficient mouse model
}

\author{
Takayoshi Sumioka ${ }^{1, *}$, Ai Kitano ${ }^{1, *}$, Kathleen C Flanders ${ }^{2}$, Yuka Okada ${ }^{1}$, Osamu Yamanaka ${ }^{1}$, Norihito Fujita ${ }^{1}$, \\ Hiroki Iwanishi ${ }^{1}$, Winston W-Y Kao ${ }^{3}$ and Shizuya Saika ${ }^{1}$
}

We investigated the effects of loss of tenascin $C$ on the healing of the stroma using incision-injured mice corneas. Tenascin $C$ was upregulated in the stroma following incision injury to the cornea. Wild-type (WT) and tenascin C-null (knockout (KO)) mice on a C57BL/6 background were used. Cell culture experiments were also conducted to determine the effects of the lack of tenascin $C$ on fibrogenic gene expression in ocular fibroblasts. Histology, immunohistochemistry and real-time reverse transcription PCR were employed to evaluate the healing process in the stroma. The difference in the incidence of wound closure was statistically analyzed in hematoxylin and eosin-stained samples between WT and KO mice in addition to qualitative observation. Healing of incision injury in corneal stroma was delayed, with less appearance of myofibroblasts, less invasion of macrophages and reduction in expression of collagen $\mid \alpha 1$, fibronectin and transforming growth factor $\beta 1$ (TGF $\beta 1$ ) in KO mice compared with WT mice. In vitro experiments showed that the loss of tenascin $C$ counteracted TGF $\beta 1$ acceleration of mRNA expression of TGF $\beta 1$, and of collagen $\mid \alpha 1$ and of myofibroblast conversion in ocular fibroblasts. These results indicate that tenascin $\mathrm{C}$ modulates wound healing-related fibrogenic gene expression in ocular fibroblasts and is required for primary healing of the corneal stroma.

Laboratory Investigation (2013) 93, 207-217; doi:10.1038/labinvest.2012.157; published online 3 December 2012

KEYWORDS: cell culture; cornea; mouse; myofibroblast; tenascin C; transforming growth factor $\beta$; wound healing

The cornea is an avascular tissue of the eye and transparent to refract light properly. An organized extracellular matrix structure is essential to the maintenance of the transparency. Once corneal stroma is injured, keratocytes adjacent to the wound are activated and undergo myofibroblast transformation to repair the damaged stroma. ${ }^{1-5}$ During healing, myofibroblasts express and polymerize extracellular matrix components for primary repair of the stroma and then remodel the connective tissue. However, excessive tissue fibrosis is also induced in certain conditions. Cell behavior during the process of wound healing in an injured ocular tissue is regulated in a complex way by various growth factors, which have critical roles in pro-fibrogenic and proinflammatory reactions. ${ }^{6,7}$ It is widely believed that transforming growth factor $\beta 1$ (TGF $\beta 1$ ) is one of the most potent cytokines involved in tissue repair and fibrosis, ie, stromal healing of the cornea. ${ }^{8}$
Tenascin $\mathrm{C}$ is one of the wound healing-related matrix macromolecules that is usually temporarily upregulated in an injured tissue, in addition to fibronectin. It is a disulfidebonded hexamer of a matrix component composed of subunits with molecular weights in the range of $120-300 \mathrm{kDa} .{ }^{9,10}$ Moreover, tenascin $\mathrm{C}$ is also abundantly detected at the invasive margin of cancer, suggesting its role at the progression/acquisition of invasive or migratory characteristics of cancer cells. ${ }^{11,12}$ It was reported that lacking tenascin $\mathrm{C}$ suppresses development of experimental liver fibrosis in mice with attenuation of fibroblastmyofibroblast conversion and reduced expression of fibrogenic cytokines. ${ }^{13}$ These findings suggest that loss of tenascin $\mathrm{C}$ may impair the fibroblast-myofibroblast conversion and primary tissue repair of the corneal stroma. Tenascin C is also expressed in keratocytes under pathological conditions. ${ }^{14,15}$ Although Matsuda et $a l^{16}$ has reported using qualitative

\footnotetext{
${ }^{1}$ Department of Ophthalmology, Wakayama Medical University, Wakayama, Japan; ${ }^{2}$ Laboratory of Cancer Biology and Genetics, Center for Cancer Research, National Cancer Institute, National Institutes of Health, Bethesda MD, USA and ${ }^{3}$ Department of Ophthalmology, The University of Cincinnati College of Medicine, Cincinnati, OH, USA

Correspondence: Dr T Sumioka, MD, PhD, Department of Ophthalmology, Wakayama Medical University, 811-1 Kimiidera, Wakayama 6410012 , Japan.

E-mail: sumioka@wakayama-med.ac.jp

"These authors contributed equally to this work.

Received 22 December 2011; revised 28 August 2012; accepted 29 August 2012
} 
histology under light microscopy that there was overall no difference in the process of tissue repair of an incision injury in the corneal stroma in the tenascin $\mathrm{C}$ knockout $(\mathrm{KO})$ mouse, attenuation of keratocyte/corneal fibroblast migration and fibronectin deposition was detected following corneal suture wounds. These findings support the hypothesis that the loss of tenascin $\mathrm{C}$ impairs the healing of the corneal stroma. To address this question, in the present study we also took an advantage of the availability of a tenascin C-null (KO) mouse of C57BL/6 background in our laboratory. In the present study, to clear a disadvantage of the qualitative assessment of the wound-healing process in the corneal stroma, we employed statistical analysis of the incidence of closure of incision injury in the central corneal stroma of WT and KO mice during healing intervals. Our statistical analysis showed that primary healing of an incision injury in the corneal stroma is impaired in the absence of tenascin C, in association with suppression of fibrogenic gene expression. Lack of tenascin $\mathrm{C}$ in cultured ocular fibroblasts counteracted TGF $\beta 1$ acceleration of expression of fibrogenic components and of myofibroblast generation.

\section{MATERIALS AND METHODS}

Experiments in vivo were approved by the DNA Recombination Experiment Committee and the Animal Care and Use Committee of Wakayama Medical University, and conducted in accordance with the Association for Research in Vision and Ophthalmology Statement for the Use of Animals in Ophthalmic and Vision Research.

\section{Incision Injury in the Central Cornea}

Wild-type C57BL/6 (WT) mice and KO mice of C57BL/6 background (RIKEN, Tokyo, Japan) were generally and topically anesthetized as previously reported. ${ }^{6,7} \mathrm{~A}$ full-thickness penetrating incision injury (1.5 $\mathrm{mm}$ in length) was produced in the central cornea of one eye by using a surgical blade (Satin Crescent, Alcon, Fort Worth, TX, USA) following administration of a mydryatic. The wound was not sutured. Ofloxacin ointment was topically administered immediately after injury and the affected eye was allowed to heal at day 0 , 5 and 10. The eye was enucleated and fixed in $4 \%$ paraformaldehyde for $48 \mathrm{~h}$. Twenty five or $25 \mathrm{WT}$, and 24 or $23 \mathrm{KO}$ eyes were prepared for histology on day 5 or 10 , respectively. Fixed specimens were routinely embedded in paraffin. Deparaffinized sections ( $7 \mu \mathrm{m}$ thickness) were stained with hematoxylin and eosin (HE) and observed under light microscopy. Histology and the degree of the closure of the incision were evaluated. The numbers of the eyes with closure of the incision were determined and were statistically analyzed as described below.

\section{Immunohistochemistry}

Deparaffinized sections were processed for immunohistochemistry as previously reported. ${ }^{6,7}$ Antibodies used were anti-Human Tenascin C (4F10TT) mouse IgG monoclonal antibody (Clone IST-9, 1:20 dilution in phosphate-buffered saline (PBS); IBL, Gunma, Japan), rat monoclonal anti-macrophage F4/80 antibody (Clone A3-1, 1:400 dilution in PBS; BMA Biomedicals, August, Switzerland), mouse monoclonal anti-cellular fibronectin antibody (1:100 dilution in PBS; Santa Cruz Biotechnology, Santa Cruz, CA, USA) and mouse monoclonal anti- $\alpha$-smooth muscle actin ( $\alpha$ SMA) antibody (1:100 dilution in PBS; Neomarker, Fremont, CA, USA). The antibody reacted with tissue antigen was visualized with 3,3'-diaminobenzidine reaction by using a commercially available immunostaining kit for sections of mouse tissue (Nichirei Biosciences, Tokyo, Japan). The specimens were counterstained with methylgreen. Secreted, active form of TGF $\beta 1$ was immunostained as previously reported by using an antisecreted, active form of TGF $\beta 1$ antibody produced by us. ${ }^{6,7}$ Specimens were observed under light microscopy (BX50; Olympus, Tokyo, Japan).

\section{Real-Time Reverse-Transcription PCR Analysis of In Vivo Gene Expression}

Healing cornea of a WT or KO mouse at day 5 or 10 was processed for total RNA extraction by using ISO GENE (Nippon Gene, Tokyo, Japan) as previously reported. ${ }^{6,7}$ Twenty corneas of 20 mice were prepared for each timepoint. One RNA sample was obtained from two corneal buttons. Taqman real-time reverse-transcription PCR (RT-PCR; TaqMan one-step RT-PCR master mix reagents kit, Applied Biosystems, Foster City, CA, USA) was performed to assay the mRNA expression level of collagen I $\alpha 1, \mathrm{TGF} \beta 1, \alpha \mathrm{SMA}$ and $\mathrm{F} 4 / 80$ by using Applied Biosystems 7300 Fast Real-Time PCR System(Applied Biosystems) as previously reported. ${ }^{6,7}$

\section{Cell Culture Experiments}

Ocular fibroblasts were obtained from a post-natal day 1 (P1) mouse as previously reported. ${ }^{16}$ The mesenchymal cells of cornea and aclera are both of a same developmental origin, ie, neural crest. The eye shells (including cornea and sclera) of P1 WT or KO mice were minced and explanted in collagen-coated $60-\mathrm{mm}$ culture dish (Iwaki Glass, Tokyo, Japan) for the outgrowth of ocular fibroblasts. Eagle's essential medium was supplemented with $10 \%$ fetal calf serum, antibiotics and an antimycotic. Intraocular structures were carefully removed before being minced. Our preliminary experiment indicated the cells to be used in the study following one passage for analysis of gene expression, because the cells started to express $\alpha \mathrm{SMA}$ after two passages.

Cells were subcultured and grown to confluence in $60-\mathrm{mm}$ culture dishes, and then treated with recombinant human TGF $\beta 1$ ( $1.0 \mathrm{ng} / \mathrm{ml}$, R\&D System, Minneapolis, MN, USA) or vehicle control in the Eagle's medium supplemented with 3\% fetal calf serum for $24 \mathrm{~h}$ The cells were then processed for total RNA extraction and Taqman real-time RT-PCR for $\alpha \mathrm{SMA}, \mathrm{TGF} \beta 1, \mathrm{TGF} \beta 2$ and collagen $\mathrm{I} \alpha 1$ as described 

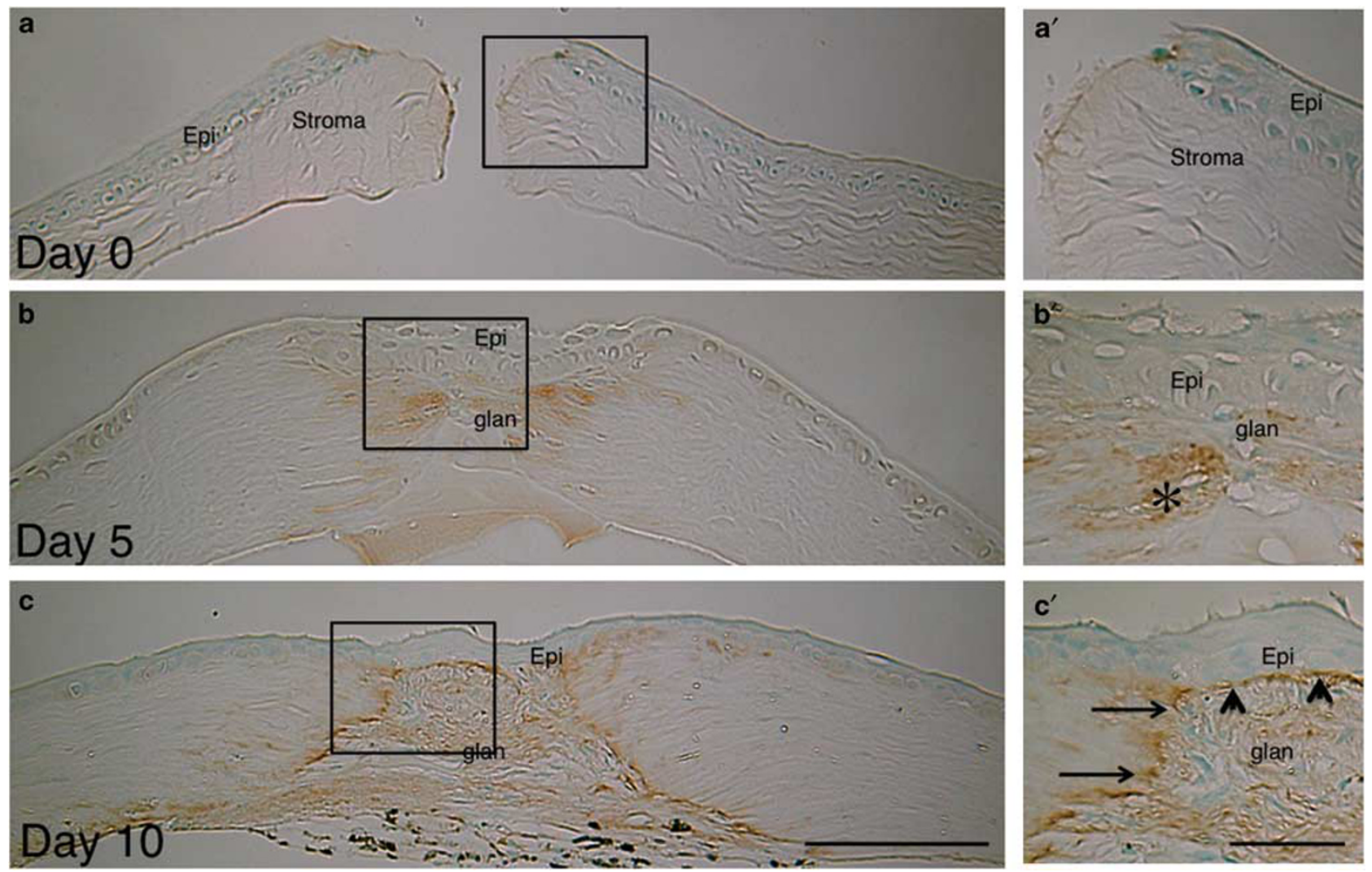

Figure 1 Protein expression of tenascin C in healing corneal stroma of a wild-type (WT) C57BL/6 mouse as observed by light microscopic immunohistochemistry. Tenascin C protein is not detected in a cornea immediately following incision (Day $\left.0, \mathbf{a}, \mathbf{a}^{\prime}\right)$. At day 5 (b, $\left.\mathbf{b}^{\prime}\right)$ and 10 (c, $\left.\mathbf{c}^{\prime}\right)$ post injury, tenascin C accumulation is observed in the stroma adjacent to the granulation tissue (glan) formed in the wound. At day 10, tenascin C protein is observed in the stroma (arrows) that faces the newly formed granulation tissue and beneath the regenerated epithelium (arrowheads) on the granulation tissue. Frames $\left(\mathbf{a}^{\prime}-\mathbf{c}^{\prime}\right)$ show the higher magnification pictures of the quadrilateral area in each of frames (a-c). epi, corneal epithelium; stroma, corneal strom; glan, granulation tissue; scale bar, $100 \mu \mathrm{m}(\mathbf{a}-\mathbf{c})$ and $25 \mu \mathrm{m}\left(\mathbf{a}^{\prime}-\mathbf{c}^{\prime}\right)$.

above. ${ }^{17,18}$ Ten dishes were prepared for each culture condition. Another set of cultures was incubated for $48 \mathrm{~h}$ with or without exogenous TGF $\beta 1$ at $1.0 \mathrm{ng} / \mathrm{ml}$ and was processed for western blotting for $\alpha \mathrm{SMA}$ protein as previously reported. ${ }^{17,18}$

\section{Statistical Analysis}

In HE histology, the numbers of the eyes with or without closure (or being occupied with newly formed granulation tissue) of the incision were determined and were statistically analyzed by using Fisher's exact test with significance as $P<0.05$. Data obtained from real-time RT-PCR were shown as means \pm s.d. ANOVA was employed in multiple group comparisons. The value of $P<0.05$ was considered as statistically significant.

\section{RESULTS}

\section{Protein Expression of Tenascin C in Healing Cornea Following an Incision Injury}

Tenascin C protein is not detected in a cornea immediately following incision (Figure 1a and $\mathrm{a}^{\prime}$ ). In day 5 post injury, tenascin $\mathrm{C}$ accumulation is observed in the stroma adjacent to the granulation tissue formed in the wound (Figure $1 \mathrm{~b}$ and $\mathrm{b}^{\prime}$ ). At day 10 , tenascin C protein is more markedly observed in the stroma that faces the newly formed granulation tissue and beneath the regenerated epithelium on the granulation tissue as compared with its expression at day 5 (Figure $1 \mathrm{c}$ and $\mathrm{c}^{\prime}$ ).

\section{Healing of KO and WT Mouse Eyes Following an Incision Injury in Cornea}

Tenascin C is reportedly upregulated in a healing, injured, corneal stroma. We therefore first examined the role of tenascin $\mathrm{C}$ in healing of corneal stroma following an incision injury. No abnormalities were observed in the eye of a $\mathrm{KO}$ mouse. The histology of an uninjured cornea and that at immediately after the injury of a KO mouse was similar to that of the WT mouse (Figure 2a and b). At day 5, the stromal injury was sealed (or closed) with granulation tissue in 17 of 25 WT mice, whereas it was found to be unclosed (remained unhealed) in 21 of $24 \mathrm{KO}$ corneas (Figure $2 \mathrm{c}$ and d). In the specimens of an unclosed wound, the epithelium showed more advanced migration on the cut surface of the stroma in $\mathrm{KO}$ corneas. The data of the incidence of closure/unclosure of 
WT
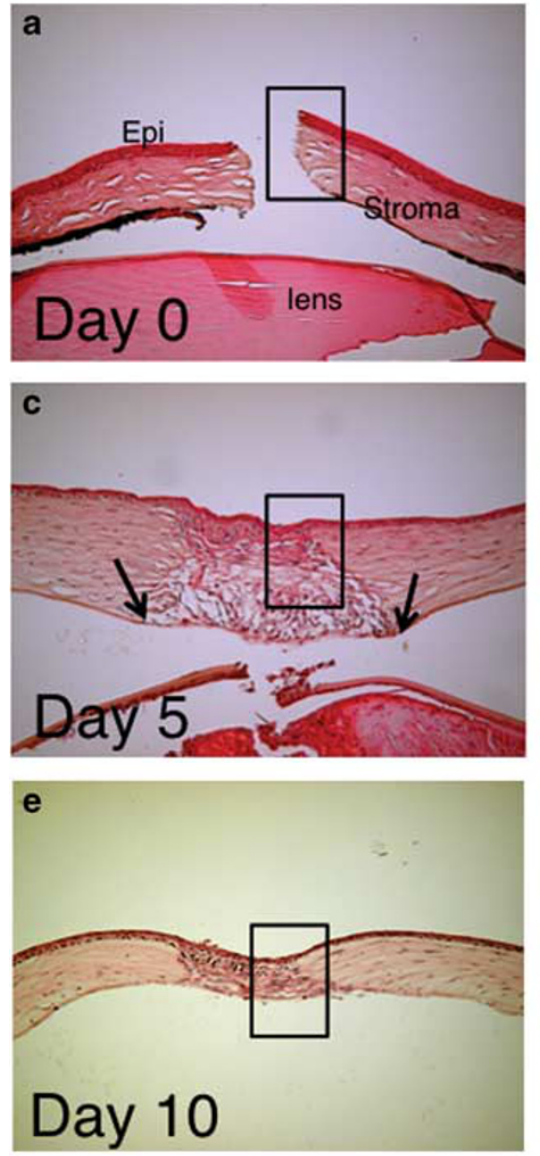

$\mathbf{a}^{\prime}$
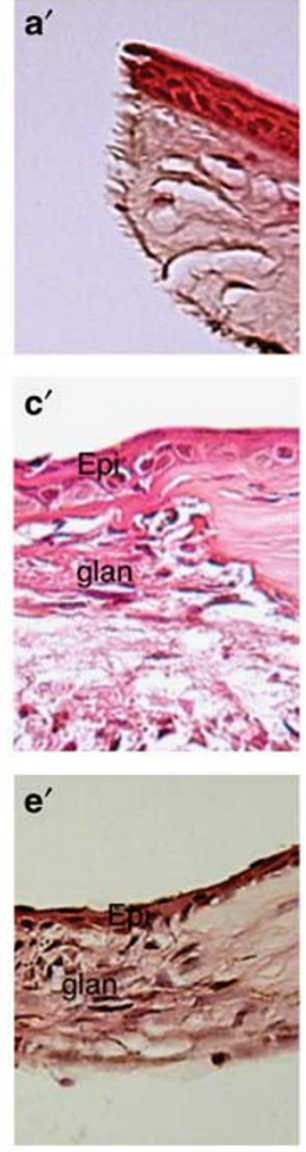

KO
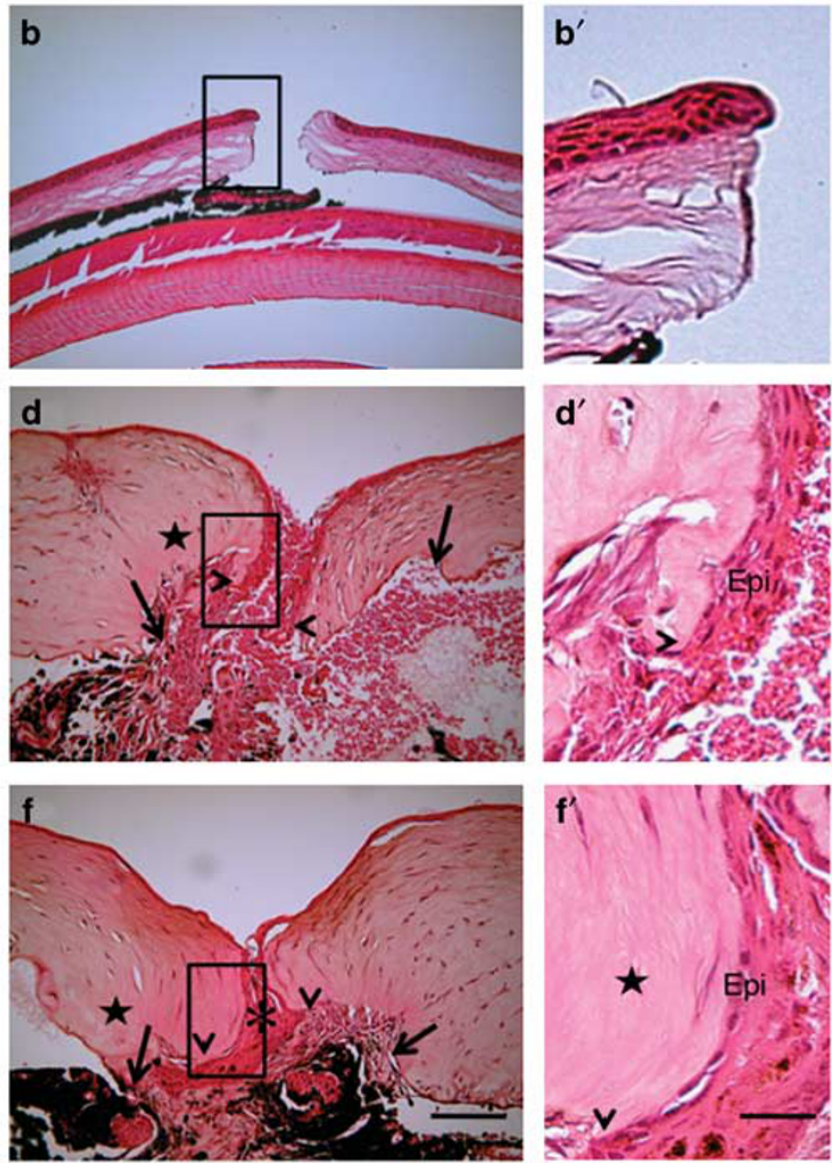

Figure 2 Healing of an incision-injured cornea of wild-type (WT) or tenascin C-null (knockout (KO)) mouse. Immediately after the incision, the injury in a KO cornea (b) was similar to that in a WT mouse (a). At a higher magnification, epithelium and stroma were found to be perpendicularly cut in both WT $\left(\mathbf{a}^{\prime}\right)$ and KO $\left(\mathbf{b}^{\prime}\right)$ mice. At day 5, the wound was sealed with fibrotic scar tissue in a WT mouse (c). Arrows indicate the cutting edge of the Descemet's membrane, although the stromal wound was not closed in a KO mouse (d). In a KO cornea, the epithelium (arrowheads) of the each side of the injury was not connected to each other, remaining the injury unclosed. Higher magnification pictures show that healing epithelium covers the granulation tissue formed in the wound in a WT mouse ( $\mathbf{c}^{\prime}$ ), whereas in a KO cornea $\left(\mathbf{d}^{\prime}\right)$ the healing epithelium does not migrate over the edge of the stromal injury (arrowhead). Arrows indicate the cutting edge of the Descemet's membrane. At day 10, the granulation (glan) tissue formed in the incision wound seemed more packed in a WT cornea (e), whereas the stromal injury was sealed with an epithelial growth (asterisk) in a KO cornea (f). At a higher magnification the healing epithelium (Epi) covers the granulation tissue (glan) in a WT tissue and in a KO cornea, healing epithelial cells (Epi) seem to fail to connect to the epithelium from the opposite side of the injury and is terminated at the end of the cutting edge of the stroma (arrowhead). Stroma of KO mice at day 5 and 10 was much thicker and seems swollen and acellular as compared with WT stroma (star). Arrows indicate the cutting edge of the Descemet's membrane. Frames $\left(\mathbf{a}^{\prime}-\mathbf{f}^{\prime}\right)$ show the higher magnification pictures of the quadrilateral area in each of Frames (a-f). Epi, corneal epithelium; stroma, corneal stroma; lens, crystalline lens; glan, granulation tissue, black arrows, the break of the Descemet's membrane; scale bar, $100 \mu \mathrm{m}(\mathbf{a}-\mathbf{f})$ and $25 \mu \mathrm{m}\left(\mathbf{a}^{\prime}-\mathbf{f}^{\prime}\right)$.

the injury were statistically significant as analyzed by using the Fisher's exact test $(P=0.00008225)$. Keratocyte population seemed to be less marked in the stroma adjacent to the wound edge in a KO cornea as compared with that in a WT cornea (indicated by a star in Figure 2d). At day 10, the incision was sealed with healing stromal tissue in 16 of 25 WT mice. On the other hand, the incision wound was found to be unclosed (unhealed) with an epithelial growth, and the stroma remained edematous in 21 of $23 \mathrm{KO}$ corneas (Figure $2 \mathrm{e}$ and $\mathrm{f}$ ). The data of the ration of healed/unhealed wounds were significant as analyzed by using the Fisher's exact test $(P=0.00007417)$. Similarly, keratocyte repopulation seemed to be less marked in the stroma adjacent to the wound edge in a KO cornea at day 10 compared with that in a WT cornea, even though the wound was found to be attached to the iris (indicated by a star in Figure 2f). Stroma of KO mice at day 5 and 10 was much thicker and seemed swollen as compared with WT stroma.

\section{Expression of Fibrogenic Components in a Healing Cornea}

Immunohistochemistry detected myofibroblast generation, as revealed by $\alpha \mathrm{SMA}$ expression. Myofibroblasts were not observed immediately after the wounding (Figure $3 \mathrm{aA}$ and 
a
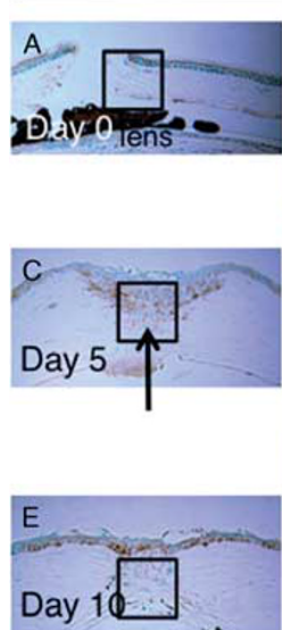

WT
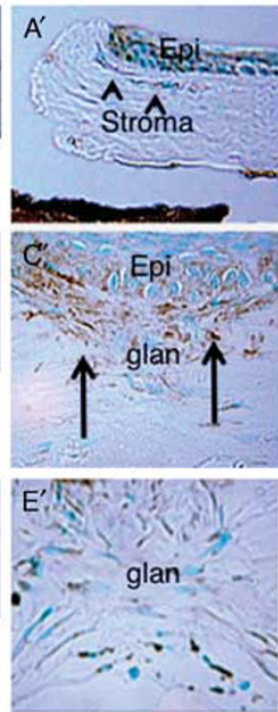

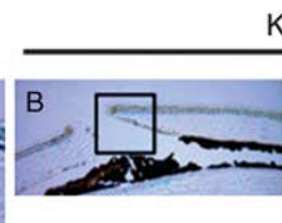

KO

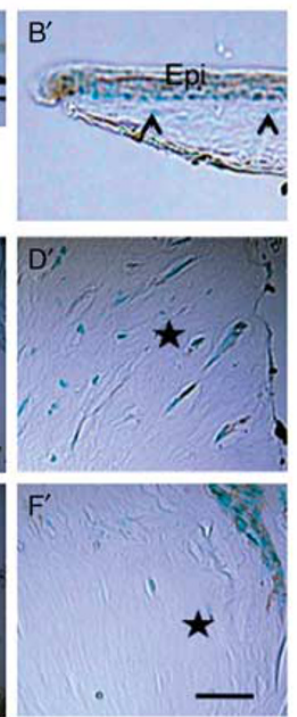

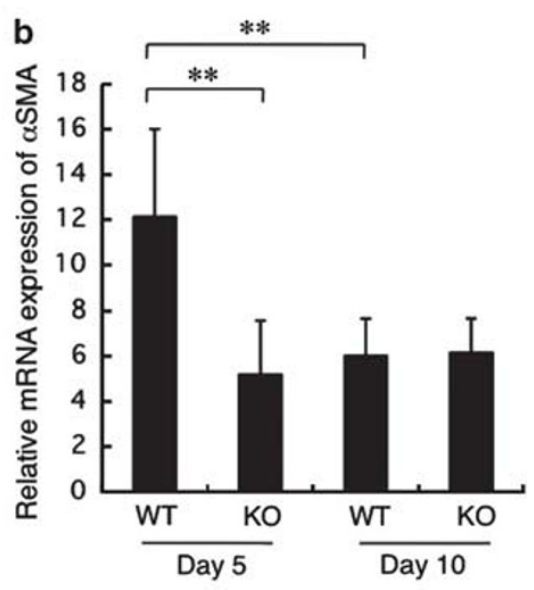

Figure 3 Expression of $\alpha$-smooth muscle actin ( $\alpha$ SMA) in an incision-injured cornea of a wild-type (WT) or a tenascin C-null (knockout (KO)) mouse as evaluated by using immunohistochemistry and real-time reverse transcription PCR (RT-PCR). (a) Myofibroblast distribution by immunohistochemical detection of $\alpha$ SMA expression. Myofibroblasts are not observed in the uninjured stroma in both WT (A) and KO (B) mice. Higher magnification pictures of WT $\left(A^{\prime}\right)$ and KO $\left(B^{\prime}\right)$ shows keratocytes (arrowheads) in the stroma. At day 5 post-incision injury, myofibroblasts are detected in the newly formed granulation tissue (arrow) in the incision injury and also in the stroma adjacent to the wound in a WT stroma (C), but almost no myofibroblasts are seen in a KO stroma (D). The higher magnification picture of WT $\left(C^{\prime}\right)$ indicates the presence of myofibrobalsts in the granulation tissue (arrows), especially beneath the regenerated epithelium. On the other hand, the KO cornea failed to form well-developed granulation tissue and the cells adjacent to the wound (star) are negative for aSMA at day $5\left(\mathrm{D}^{\prime}\right)$. At day $10 \alpha \mathrm{SMA}$-positive cells seem to be less as compared with that at day 5 in the granulation or scar tissue in a WT stroma $\left(E, E^{\prime}\right)$. At this timepoint, myofibroblasts are not observed in the tissue formed in the injury in a KO cornea $(F$, star in frame $F^{\prime}$ ). Frames $A^{\prime}-F^{\prime}$ show the higher magnification pictures of the quadrilateral area in each of Frames A-F. Nuclear staining, methylgreen; Epi, corneal epithelium; stroma, corneal stroma; lens, crystalline lens; glan, granulation tissue; bar, $100 \mu \mathrm{m}(\mathrm{A}-\mathrm{F}), 20 \mu \mathrm{m}\left(\mathrm{A}^{\prime}-\mathrm{F}^{\prime}\right)$. (b) Relative $\alpha \mathrm{SMA}$ mRNA expression in the cornea of WT and KO mice as examined by real-time RT-PCR. At day 5, mRNA expression of $\alpha$ SMA is significantly higher in a WT cornea as compared with that in a KO cornea. At day 10, its expression decreases in a WT cornea, whereas it is not altered by the loss of tenascin C. ${ }^{*} P<0.01$.

$\mathrm{aB})$ and were detected in day 5 post-incision in a WT cornea (Figure $3 \mathrm{aC}$ ). Myofibroblasts were observed in the granulation tissue formed in the injury wound, as well as in the stroma adjacent to the edge of the incision. On the other hand, $\alpha$ SMA-labeled myofibroblasts were much less observed in the injured stroma of a $\mathrm{KO}$ mouse at this timepoint (Figure $3 \mathrm{aD}$ ). Real-time RT-PCR indicated that the expression level of $\alpha \mathrm{SMA}$ mRNA was much higher in the WT healing cornea as compared with the KO stroma at day 5 (Figure 3b). At day 10, immunohistochemical detection of aSMA seemed to decrease as compared with that at day 5 in WT mice (Figure $3 \mathrm{aE}$ ). In a KO corneal stroma, the expression of $\alpha \mathrm{SMA}$ as detected by immunohistochemistry seemed to increase at day 10 as compared with that at day 5 in $\mathrm{KO}$ corneas (Figure 3aF). Real-time RT-PCR showed that at day 10 , the mRNA of $\alpha \mathrm{SMA}$, not the protein, expression decreases in a WT cornea, whereas it was readily detected in a KO cornea. However, a significant difference between a WT and a $\mathrm{KO}$ sample was not detected at this timepoint (Figure $3 \mathrm{~b}$ ).

Fibronectin is a typical wound healing-related adhesive matrix macromolecule. In the current study, fibronectin was not detected in the corneal tissue immediately after the incision injury in both WT and KO mice (Figure 4aA and $\mathrm{aB})$. At day 5 , the granulation tissue formed in the wound labeled for fibronectin in a WT cornea (Figure $4 \mathrm{aC}$ ), whereas not in a $\mathrm{KO}$ tissue (Figure $4 \mathrm{aD}$ ). At day 10, fibronectin was still faintly observed in the healing stroma of a WT cornea (Figure 4aE), although its immunoreactivity seemed less marked as compared with that at day 5. Such immunoreactivity was not observed in a $\mathrm{KO}$ cornea at this timepoint (Figure 3aF).

Although type I collagen is the major extracellular matrix component, its mRNA upregulation indicates the presence of fibrogenic healing process of the connective tissue. TGF $\beta 1$ is the major growth factor that modulates fibrogenic reaction in an injured tissue. We therefore examine if lacking tenascin $\mathrm{C}$ alters the expression of these two components in a healing cornea. The results showed that mRNA expression of collagen $\mathrm{I} \alpha \mathrm{l}$ (Figure $4 \mathrm{~b}$ ) and TGF $\beta 1$ (Figure $5 \mathrm{a}$ ) was significantly higher in a WT cornea as compared with that in a KO cornea at day 5 . At day 10, expression of these components decreased in a WT cornea. However, a significant difference of the expression level of these components between WT and KO samples was not detected at this timepoint (Figures $4 \mathrm{a}$ and $5 \mathrm{~b}$ ). 
a
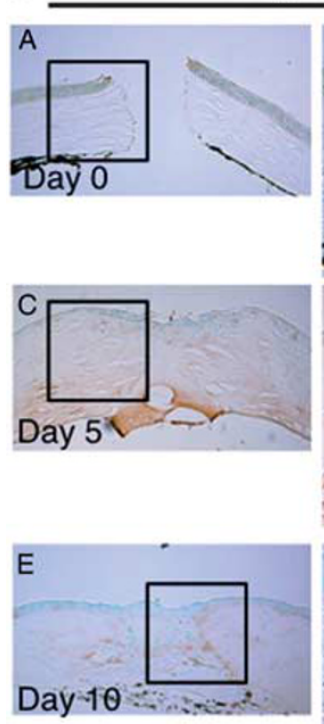

WT
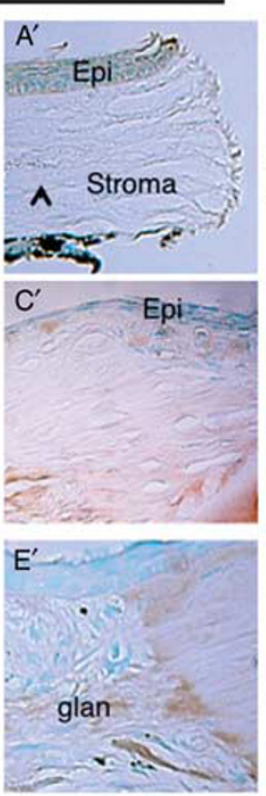
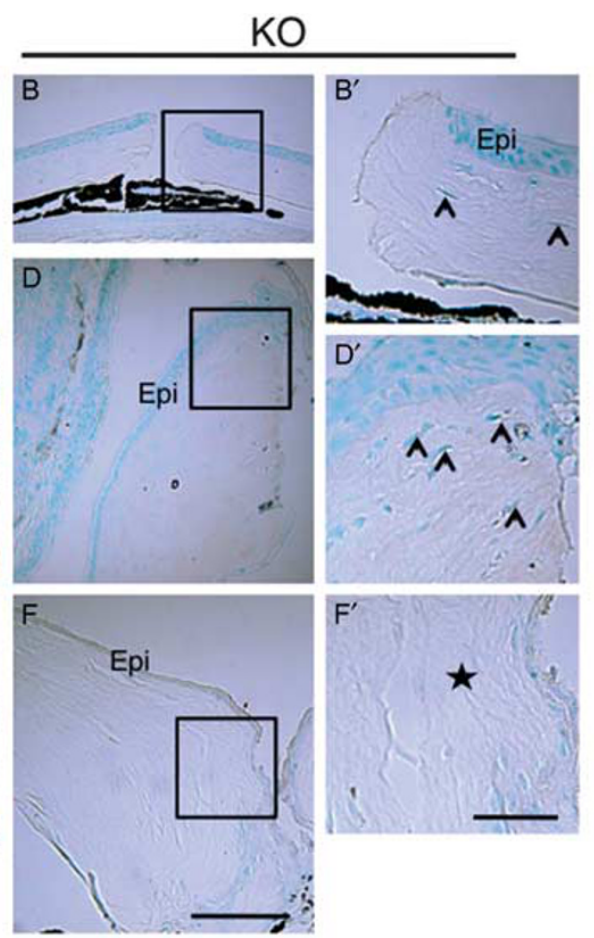

b

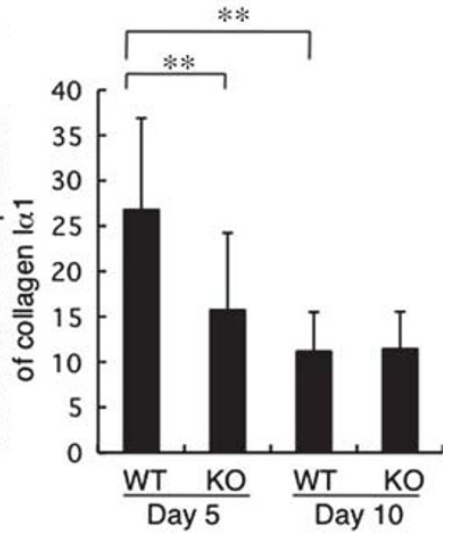

Figure 4 Expression of extracellular matrix components in a healing tenascin C-null (knockout (KO)) cornea following an incision injury. (a) Protein expression of cellular fibronectin in a healing, incision-injured, cornea of a wild-type (WT) or a KO mouse as examined by immunohistochemistry. Cellular fibronectin is not detected in the corneal tissue of a WT $\left(A, A^{\prime}\right)$ and a KO $\left(B, B^{\prime}\right)$ mouse immediately after the incision injury. At day 5 postincision injury, cellular fibronectin are detected in the stroma adjacent to the wound and in the newly formed granulation tissue in the incision injury in a WT stroma (C), but not seen in a KO stroma (D). The higher magnification picture of a WT cornea ( $\left.C^{\prime}\right)$ indicates the accumulation of cellular fibronectin in the stroma and minority of the basal epithelial cells. On the other hand, the KO cornea failed to form well-developed granulation tissue and the cells (arrowheads) adjacent to the wound are negative for cellular fibronectin at day $5\left(\mathrm{D}^{\prime}\right)$. At day 10 post-incision injury, cellular fibronectin are detected mainly in the stroma adjacent to the wound in a WT stroma $\left(E, E^{\prime}\right)$, but not seen in a KO stroma ( $\left.F\right)$. The higher magnification picture of a KO cornea $\left(\mathrm{F}^{\prime}\right)$ show that the stroma in a KO cornea shows less cellularity at day $10\left(\mathrm{~F}^{\prime}\right)$. Frames $\mathrm{A}^{\prime}-\mathrm{F}^{\prime}$ show the higher magnification pictures of the quadrilateral area in each of Frames A-F. Nuclear staining, methylgreen; Epi, corneal epithelium; stroma, corneal stroma; glan, granulation tissue; scale bar, $100 \mu \mathrm{m}(\mathrm{A}-\mathrm{F})$ and $30 \mu \mathrm{m}\left(\mathrm{A}^{\prime}-\mathrm{F}^{\prime}\right)$. (b). mRNA expression of collagen $1 \alpha 1$ chain in a healing incision-injured cornea. The loss of tenascin $C$ significantly suppresses mRNA expression of collagen $\mid \alpha 1$ at day 5 . In a WT cornea, expression level of collagen $\mid \alpha 1$ decreases at day 10 as compared with that at day 5. At day 10, there is no difference of the expression level of collagen I $\alpha 1$ between WT and KO corneas. ${ }^{*} P<0.01$.

As real-time RT-PCR measures total expression level of TGF $\beta 1$ message, we next measured the level of secreted, active form of TGF $\beta 1$ in the tissue by using a specific antibody (Figure 5b). Corneal epithelium and stroma were unstained for the secreted, active form of TGF $\beta 1$ in both WT and $\mathrm{KO}$ mice (Figure $5 \mathrm{bA}$ and $\mathrm{bA}^{\prime}$, and $\mathrm{bB}$ and $\mathrm{bB}^{\prime}$ ) immediately after the incision wounding. At day 5 , active TGF $\beta 1$ was detected in the stroma adjacent to the wound in a WT cornea (Figure $5 b$ and C), whereas the stroma that faces the incision injury was free from the active form of TGF $\beta 1$ in a KO mouse (Figure $5 \mathrm{bD}$ and $\mathrm{bD}^{\prime}$ ). At a higher magnification, active TGF $\beta 1$ was accumulated in the stroma beneath the regenerated epithelium (Figure $5 b C^{\prime}$ ). At day 10, active, secreted form of TGF $\beta 1$ was detected in the healing stroma of both WT and KO cornea (Figure $4 \mathrm{~b}$ and E, F). In both cases, active TGF $\beta 1$ was more markedly detected in subepithelial stroma in the central healing stroma (Figure $5 \mathrm{bE}^{\prime}$ and $\mathrm{bF}^{\prime}$ ).

\section{Macrophage Invasion}

Macrophages have a crucial role in the process of tissue repair by expressing various cytokines/growth factors, including TGF $\beta 1$. F4/80 immunohistochemistry did not detect macrophages in WT and KO corneas immediately following injury (Figure $6 \mathrm{aA}, \mathrm{aB}$ and $\mathrm{aB}^{\prime}$ ). At day 5, abundant F4/80-labeled macrophages were detected in the granulation tissue formed in the wound of a WT mouse (Figure 6aC), whereas very few immunolabeled cells were seen in a $\mathrm{KO}$ cornea (Figure 6aD). At a higher magnification, granulation tissue formed in the wounded stroma was occupied with F4/ 80-labeled cells in a WT cornea (Figure 5aA'). Such labeled cells were seen in a $\mathrm{KO}$ stroma (Figure $6 \mathrm{aD}^{\prime}$ ) At day 10, macrophage invasion was reduced in a WT cornea (Figure 6aE). At this timepoint, macrophages were not seen in the healing stroma of a $\mathrm{KO}$ cornea (Figure $6 \mathrm{aF}$ ). We then obtained a semi-quantitative data for mRNA expression of F4/80 antigen by using real-time RT-PCR. mRNA expression 


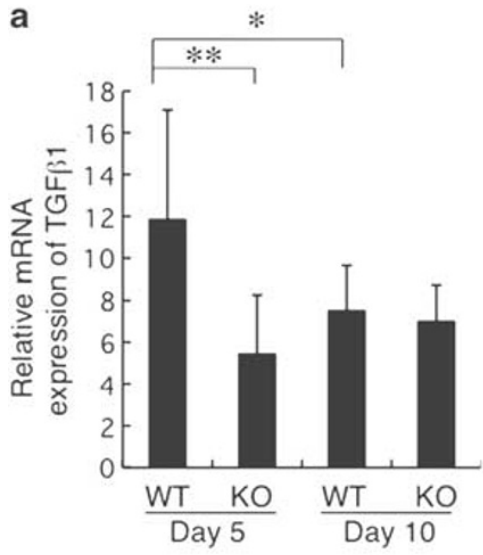

b

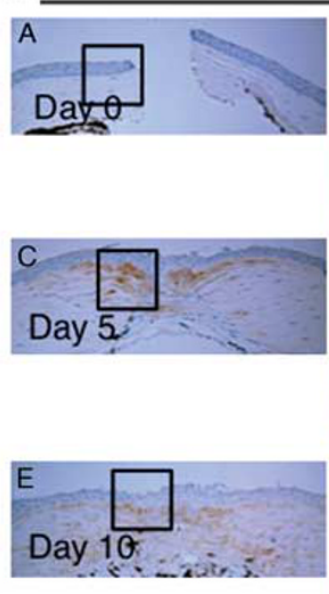

WT
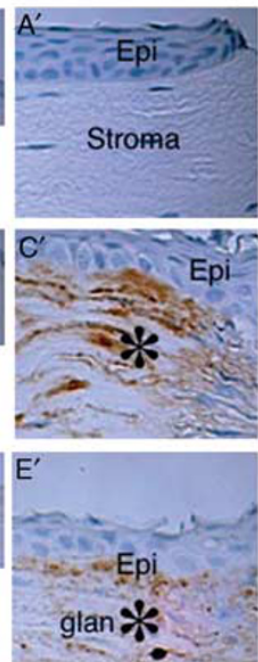

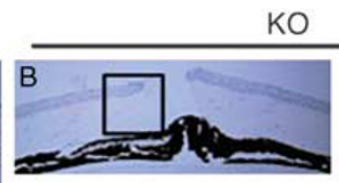

KO
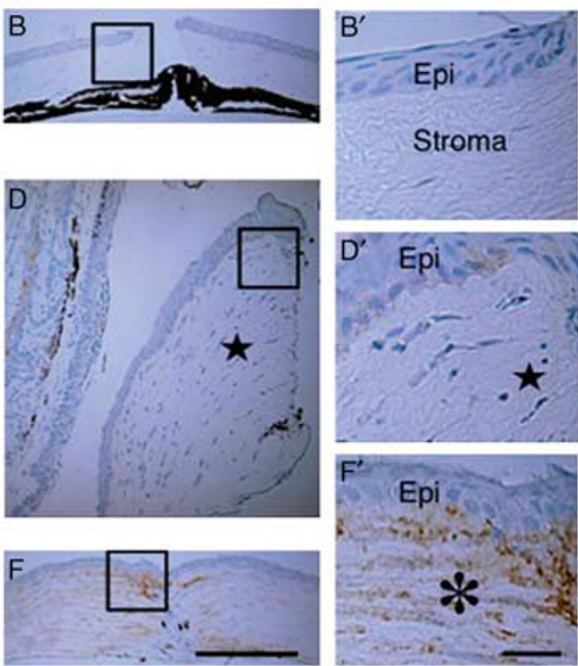
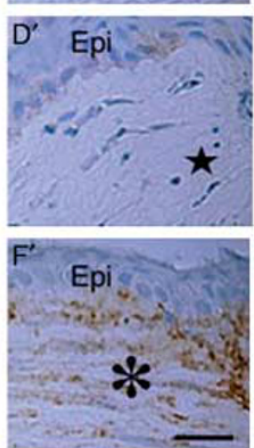

Figure 5 (a) Relative mRNA expression of transforming growth factor $\beta 1$ (TGF $\beta 1$ ) in the cornea of wild-type (WT) and tenascin C-null (knockout (KO)) mice as examined by real-time reverse transcription PCR (RT-PCR). At day 5, mRNA expression of TGF $\beta 1$ is significantly higher in a WT cornea as compared with that in a KO cornea. At day 10 its expression decreases in a WT cornea. However, a significant difference between a WT and a KO samples was not detected at this timepoint. ${ }^{*} P<0.05$, ${ }^{* *} P<0.01$. (b) Immunohistochemical detection of secreted, active form of TGF $\beta 1$ in a healing cornea. Secreted, activated form of TGF $\beta 1$ is not detected in a cornea of a WT $\left(A, A^{\prime}\right)$ or a KO $\left(B_{1}, B^{\prime}\right)$ cornea immediately after the incision wounding. At day 5 , active form of TGF $\beta 1$ is detected in the stroma adjacent to the wound in a WT cornea, whereas the stroma that faces the incision injury is free from the active form of TGF $\beta 1$ in a KO mouse. A higher magnification picture shows that active TGF $\beta 1$ (asterisk) is found to be deposited beneath the regenerated epithelium of a WT healing cornea $\left(C^{\prime}\right)$. Matrix as well as keratocytes (star) are not labeled for active TGF $\beta 1$ in a KO tissue at this timepoint $\left(\mathrm{D}^{\prime}\right)$. At day 10 , active, secreted form of TGF $\beta 1$ is detected in the healing stroma of both WT (E) and KO (F) cornea. Active TGF $\beta 1$ (asterisk) is mainly detected in the stroma beneath the regenerated epithelium of a WT $\left(E^{\prime}\right)$ and $K O\left(F^{\prime}\right)$ healing cornea. Frames $A^{\prime}-F^{\prime}$ show the higher magnification pictures of the quadrilateral area in each of frames A-F. Nuclear staining, hematoxylin; epi, corneal epithelium; stroma, corneal stroma; glan, granulation tissue; scale bar, $100 \mu \mathrm{m}(\mathrm{A}-\mathrm{F})$ and $25 \mu \mathrm{m}\left(\mathrm{A}^{\prime}-\mathrm{F}^{\prime}\right)$.

a
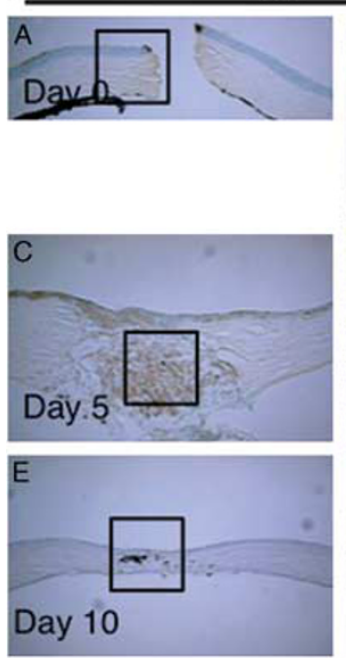

$\mathrm{KO}$
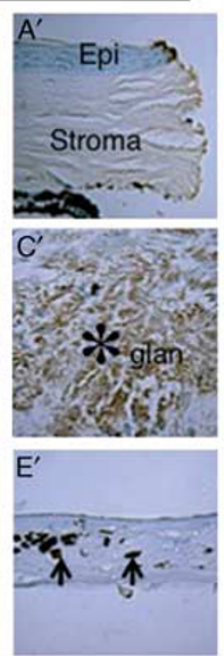
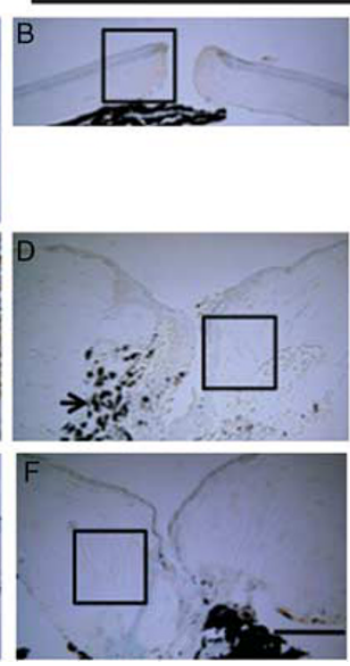

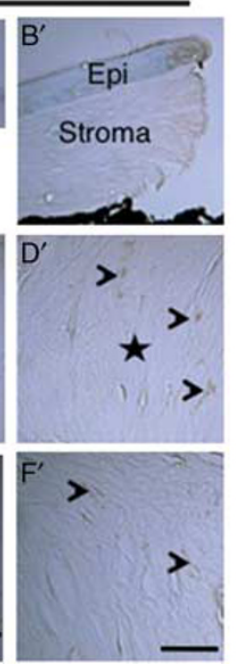

b

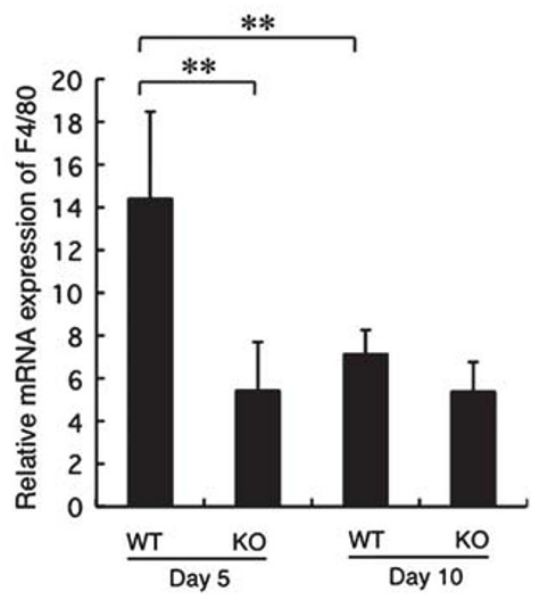

Figure 6 Expression of a macrophage marker, F4/80, in an incision-injured cornea of a wild-type (WT) or a tenascin C-null (knockout (KO)) mouse as evaluated by using immunohistochemistry and real-time reverse transcription PCR (RT-PCR). (a) Macrophage distribution by immunohistochemical detection of $F 4 / 80$ expression. Macrophage is not observed in the uninjured stroma in both WT $\left(A, A^{\prime}\right)$ and $K O\left(B, B^{\prime}\right)$ mice. At day 5 post-incision injury, macrophages are detected in the newly formed granulation tissue in the incision injury and also in the stroma adjacent to the wound in a WT stroma $\left(C, C^{\prime}\right)$, but a few macrophages are seen in a KO stroma $\left(D, D^{\prime}\right)$. At day 10, F4/80-positive macrophage is not seen in the scar tissue formed in the wound of a WT $\left(E, E^{\prime}\right)$. At this timepoint, macrophage is not observed in unhealed stroma of a KO cornea $\left(F, F^{\prime}\right)$. Granulation or scar tissue contain pigment granules (arrows) derived from iris in frames $D$ and $E^{\prime}$. Frames $A^{\prime}-F^{\prime}$ show the higher magnification pictures of the quadrilateral area in each of Frames A-F. Nuclear staining, methylgreen; Epi, corneal epithelium; stroma, corneal stroma; glan, granulation tissue; scale bar, $100 \mu \mathrm{m}(\mathrm{A}-\mathrm{F})$ and $30 \mu \mathrm{m}\left(\mathrm{A}^{\prime}-\mathrm{F}^{\prime}\right)$. (b) Relative F4/80 mRNA expression in the cornea of WT and KO mice as examined by real-time RT-PCR. At day 5, mRNA expression of F4/80 is significantly higher in a WT cornea as compared with that in a KO cornea. Its mRNA expression decreases at day 10 as compared with that at day 5 in a WT mouse cornea. A significant difference in the expression level of F4/80 between a WT and a KO samples was not detected at this timepoint. ${ }^{*} P<0.01$. 

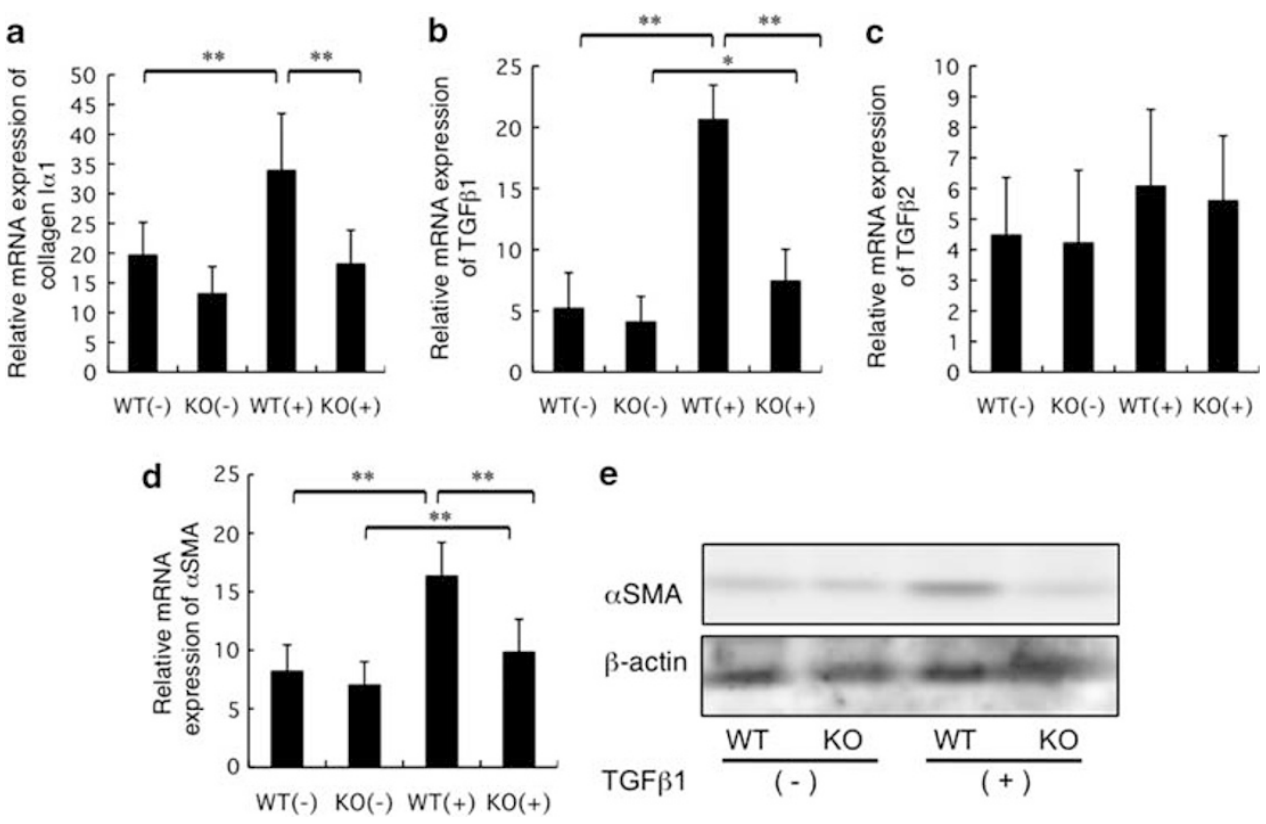

Figure 7 Expression of fibrogenic components in the ocular fibroblasts derived from post-natal day 1 (P1) wild-type (WT) and tenascin C-null (knockout (KO)) mice. Exogenous transforming growth factor $\beta 1$ (TGF $\beta 1$ ) at $1.0 \mathrm{ng} / \mathrm{ml}$ upregulates mRNA expression of collagen $\mid \alpha 1$ (a) and TGF $\beta 1$ (b), but not TGF $\beta 2$ (c) in WT ocular fibroblasts, and also increases TGF $\beta 1$ mRNA expression in KO cells (b). The loss of tenascin C counteracts the upregulation of collagen $\mid \alpha 1$ and TGF $\beta 1$ by adding TGF $\beta 1$. Expression of $\alpha$-smooth muscle actin ( $\alpha \mathrm{SMA}$ ) is the hallmark of myofibroblast generation and tissue fibrosis. Adding exogenous TGF $\beta 1$ enhances expression of $\alpha$ SMA mRNA, which is counteracted by lacking tenascin $C$ in cultured ocular fibroblasts (d). Western blotting further shows that exogenous TGF $\beta 1$ increase protein expression of $\alpha$ SMA and this promotion is counteracted by the loss of tenascin C. ${ }^{* *} P<0.01$.

of F4/80 antigen was higher in the healing WT cornea as compared with $\mathrm{KO}$ cornea at day 5, but there was no difference at day 10 (Figure 6b).

\section{Cell Culture Experiments}

In the ocular fibroblasts used here, adding exogenous TGF $\beta 1$ significantly upregulated mRNA expression of collagen $\mathrm{I} \alpha 1$ and TGF $\beta 1$, but TGF $\beta 2$ mRNA expression was not altered by exogenous TGF $\beta 1$. Loss of tenascin C blocked the TGF $\beta 1$ induced upregulation of mRNA expression for both collagen I $\alpha 1$ (Figure 7a) and TGF $\beta 1$ (Figure 7b). Expression of TGF $\beta 2$ was not significantly changed by the loss of tenascin $\mathrm{C}$ in the cells (Figure 7c), either in the presence or absence of TGF $\beta 1$.

A similar pattern of mRNA expression of $\alpha$ SMA was observed. Addition of exogenous TGF $\beta 1$ increased the mRNA expression level of $\alpha \mathrm{SMA}$ (Figure $7 \mathrm{~d}$ ) in WT fibroblasts, whereas loss of tenascin $\mathrm{C}$ attenuated the upregulation of mRNA expression of $\alpha$ SMA by exogenous TGF $\beta 1$ (Figure $7 \mathrm{~d}$ ). Furthermore, $\alpha \mathrm{SMA}$ protein expression level increased following TGF $\beta 1$ treatment of WT fibroblasts, but no upregulation of $\alpha \mathrm{SMA}$ was detected in tenascin $\mathrm{C} \mathrm{KO}$ fibroblasts (Figure 7e).

\section{DISCUSSION}

In the present study, we first showed that the healing of the full-thickness incision in the cornea was statistically significantly delayed in the $\mathrm{KO}$ mice as compared with the WT mice. The incision injury in the corneal stroma was occupied with granulation tissue (primary healing) at day 5 in 17 of 25 WT corneas, whereas the wound edge was not adhered to each other in 21 of $24 \mathrm{KO}$ mice. Even at day 10, fibrotic adhesion between in the wound were observed only in 2 of 23 KO mice compared with 16 of 25 WT corneas.

Further analysis was conducted to elucidate the mechanism underlying the impaired stromal healing in a $\mathrm{KO}$ mouse. Immunohistochemistry suggest that generation of $\alpha \mathrm{SMA}$ labeled myofibroblasts, the hallmark of stromal wound healing and tissue fibrosis, in the corneal stroma adjacent the wound was severely attenuated by the loss of tenascin C. The real-time RT-PCR analysis also showed less expression of aSMA mRNA in the KO cornea as compared with the WT cornea at day 5 post injury. HE histology shows that mesenchymal cells derived from the iris might exhibit a minimum contribution to the stromal healing, because each iris was not found to be directly adhered to the corneal injury in each WT specimen. In a KO cornea, the iris was attached to the corneal wound at day 10 probably because of the prolonged exposure of the stromal cut surface due to delayed healing. Fibronectin is a major wound healing-related adhesive matrix molecule in cornea like that in various tissues, and is detected in plasma (plasma fibronectin) and expressed in local cells (cellular fibronectin). Our present immunohistochemistry clearly showed that the loss of tenascin $\mathrm{C}$ reduced the upregulation of cellular fibronectin at the injury site of the cornea that coincides with the previous report by Matsuda et al. ${ }^{16}$ Real-time RT-PCR indicated that mRNA 
expression of collagen $\mathrm{I} \alpha 1$ chain was also more marked in a WT cornea as compared with a KO cornea at day 5 post wounding, but not at day 10 . These findings taken together indicate that tenascin $\mathrm{C}$ is involved in the expression of tissue fibrosis-related components in vivo. Matsuda et al ${ }^{16}$ reported that the final healing outcome was similar between in a WT mouse and in their tenascin C-deficient mice of background of $\mathrm{C} 3 \mathrm{H}$ or $\mathrm{BALB} / \mathrm{C}$, although detailed histological analysis showed findings similar to ours, suppression of expression of fibronectin and cornmeal fibroblast population with lacking tenascin C. It is to be answered if the background of mouse strain might affect the healing outcome in an incision injury in cornea of tenascin C-deficient mice. Indeed in an experimental model of pulmonary fibrosis, mouse strains affect the degree of the fibrosis. ${ }^{19}$

As TGF $\beta 1$ is the major growth factor involved in tissue fibrosis and modulating the expression level of collagen I and fibronectin, and myofibroblast generation, we next evaluated the expression level of TGF $\beta 1 .{ }^{19}$ Real-time RT-PCR and showed that loss of tenascin $C$ reduced its expression level in the healing cornea at day 5, but not at day 10. Furthermore, immunohistochemistry indicated that expression of secreted, activated form of TGF $\beta 1$ was also suppressed by the loss of tenascin $\mathrm{C}$ at day 5 , but not at day 10 . This finding suggests the critical role of the attenuation of TGF $\beta 1$ expression in a $\mathrm{KO}$ cornea in the $\mathrm{KO}$ phenotype of healing of the incision injury of the cornea. Although TGF $\beta 1$ is one of the growth factors most involved in the phenotypic change of a fibroblast into a myofibroblast, tissue fibronectin is also required for this phenomenon. ${ }^{20}$ Thus, in the present study less appearance of myofibroblasts in the $\mathrm{KO}$ tissue at day 10 might be explained by the low level of immunohistochemically detected cellular fibronectin. Besides its fibrogenic effects, TGF $\beta 1$ is chemoattractant to macrophages, which, in turn, is one of the major source of TGF $\beta 1$ in a healing tissue. Thus, we then examined the population of macrophages in the injured cornea of WT and KO mice. We previously reported an impairment of macrophage infiltration in a cauterized cornea by the loss of tenascin C. ${ }^{21}$ Immunohistochemistry suggested that accumulation of F4/80-labeled macrophages was less in a $\mathrm{KO}$ wound as compared with a WT wound at day 5. Realtime RT-PCR indicated that expression of F4/80 mRNA decreased at day 10 as compared with that at day 5. F4/80 expression was reduced by the loss of tenascin $C$ at day 5 . Suppression of macrophage infiltration, in turn, might account for further reduction of TGF $\beta 1$ level in tissue.

We then conducted in vitro experiments by using cultured fibroblasts obtained from a KO mouse eye. These experiments showed that adding exogenous TGF $\beta 1$ upregulated mRNA expression of TGF $\beta 1$ and collagen I $\alpha 1$, but did not alter the expression level of TGF $\beta 2$. Lacking tenascin $C$ decreased mRNA expression of TGF $\beta 1$ and collagen $\mathrm{I} \alpha 1$, but not TGF $\beta 2$, in the cells in the presence of exogenous TGF $\beta 1$. Generation of myofibroblasts from fibroblasts is also a hallmark of granulation tissue formation and tissue scarring. Adding TGF $\beta 1$ significantly upregulated mRNA and protein expression of $\alpha \mathrm{SMA}$, the marker for the myofibroblast, in cultured ocular fibroblasts. We then showed that loss of tenascin $\mathrm{C}$ counteracted upregulation of $\alpha \mathrm{SMA}$ mRNA and protein by exogenous TGF $\beta 1$. These in vitro findings suggest that lacking tenascin $\mathrm{C}$ attenuates activation of TGF $\beta$-related cellular behaviors in vitro. A similar mechanism also might underlie the impaired healing of the KO corneal stroma in vivo besides the reduction of tissue TGF $\beta 1$ level and suppression of macrophage infiltration.

The effects of lacking tenascin $\mathrm{C}$ on the healing process of the corneal or cutaneous tissue have been previously studied. Matsuda $\mathrm{et} \mathrm{al}^{16}$ reported that there was overall no difference in the stromal repair by using qualitative histology and light microscopy without statistical analysis. ${ }^{14}$ They described that the loss of tenascin $\mathrm{C}$ attenuates expression of wound healing-related components (corneal fibroblast migration and fibronectin deposition) in a suture wound in a corneal stroma in mice. The report might support our statistical conclusion of the impairment of stromal repair in a $\mathrm{KO}$ mouse. Fosberg et al22 reported the loss of tenascin C suppresses the expression of level of fibronectin in the healing granulation tissue, but there was overall no difference in healing of skin and nerve injuries in a tenascin C-deficient mouse. They also evaluated the healing process by using the histology methods, but not statistical analysis of the size of the wound. Possible suppression of healing by the reduction of fibronectin might be counteracted (or masked) by abundant wound healing-promoting factors and inflammatory cells supplied by the blood in the $\mathrm{KO}$ mouse skin wound. The difference of the wound-healing process between these two tissues might depend on the structure (including presence/absence of the blood vessels). Sta Iglesia et al ${ }^{23}$ reported deletion of tenascin $\mathrm{C}$ did not perturb corneal epithelial wound healing, but they failed to examine the stromal tissue repair.

Previous reports also indicate that loss of tenascin C attenuates tissue fibrosis in the liver and lung, which show less severe fibrosis and suppression of TGF $\beta$ signaling in the tenascin C KO mouse as compared with a WT mouse. In these projects, lacking tenascin $\mathrm{C}$ suppresses the progression of undesirable tissue fibrosis or generation of myofibroblasts from mesenchymal cells in vitro. The present finding that the loss of tenascin $\mathrm{C}$ attenuates the healing of the corneal stroma coincides with these previous reports.

The exact mechanism that explains blocking of TGF $\beta$ signal by lacking tenascin $C$ remains to be identified. We previously reported that loss of osteopontin, another $\alpha 9$ integrin-related extracellular matrix component like tenascin C, impairs healing of an incision injury similar to that employed in the present study, and that expression of fibrogenic components in cultured ocular fibroblasts was suppressed by the loss of this molecule. ${ }^{24}$ Our in vitro experiment revealed that lacking osteopontin inhibited phosphorylation of Smad3 and 
p38 in cultured ocular fibroblasts that might explain the mechanism of attenuation of TGF $\beta$-related fibrogenic reaction in osteopontin-null fibroblasts. ${ }^{25}$ As for the mechanism of impairment of TGF $\beta$-related healing and fibrogenic gene expression by the loss of tenascin $\mathrm{C}$ was reported in experimental lung fibrosis model in mice, ${ }^{26-29}$ this report also showed that lacking tenascin $\mathrm{C}$ decreases the level of total Smad3 (not Smad2), ${ }^{30}$ but did not inhibit the phosphorylation of $S \operatorname{mad} 3$, as examined by western blotting. The authors of this report speculate that reduction of total Smad3 protein might account for the impairment of TGF $\beta /$ Smad3 signal and resultant inhibition of fibrogenic behaviors of fibroblasts in lung tissue. However, our experiments showed, on the other hand, that the loss of tenascin $\mathrm{C}$ does not affect both the level of phosphorylation of $\operatorname{Smad} 2 / 3$ and p38 and total level of Smad3 protein (data not shown). Therefore, the mechanism underlying the attenuation of fibrogenic gene expression in ocular fibroblasts by lacking tenascin $\mathrm{C}$ might not be similar to that of tenascin C-null lung fibroblasts and also the ocular fibroblasts derived from a mouse lacking osteopontin.

Interaction between integrin-derived signals and TGF $\beta$ related signals are reported in various cell types. Activation of an integrin could initiate TGF $\beta /$ Smad signaling via interaction with TGF $\beta$ receptor. ${ }^{31,32}$ TGF $\beta$-induced phenotypic changes were not observed in cells in suspension and were dependent on $\beta 1^{33}$ or $\alpha 3 \beta 1$-integrin ${ }^{34}$. TGF $\beta$-mediated cellular transdifferentiation to a more fibrogenic phenotype, such as the myofibroblast or EMT, appears to require integrins. For example, $\alpha \mathrm{v} \beta 3$-integrin interacts with T $\beta$ RII and enhances TGF $\beta$-induction of lung fibroblast proliferation. ${ }^{35}$ Further, siRNA to $\beta 3$-integrin inhibited TGF $\beta$-induced EMT and migration of mouse mammary gland epithelial cells by preventing the $\mathrm{T} \beta \mathrm{R}$-interaction with the integrin and subsequent p38 MAPK activity without affecting Smad phosphorylation. ${ }^{36}$ T $\beta$ RII association with $\alpha \mathrm{v} \beta 5$-integrin was also found in sclerodermal fibroblasts, and subsequent FAK activity is required for myofibroblastic differentiation. ${ }^{37}$ These reports strongly suggest the involvement of tenascin $\mathrm{C}$ integrin binding might exert a specific effect on Smad signal. Further in vitro study is needed to uncover this point.

\section{ACKNOWLEDGEMENTS}

This study was supported with a Grant from the Ministry of Education, Science, Sports and Culture of Japan (C19592036 to SS, C40433362 to TS), Mitsui Life Social Welfare Foundation, Mochida Memorial Foundation, Takeda Science Foundation and Uehara Foundation (to SS). We appreciate Prof Dr James V. Jester, Gavin Herbert Eye Institute, University of California, Irvine, for his proofreading and suggestions on the manuscript draft.

\section{DISCLOSURE/CONFLICT OF INTEREST}

The authors declare no conflict of interest.

1. Brodovsky SC, McCarty CA, Snibson G, et al. Management of alkali burns: an 11-year retrospective review. Ophthalmology 2000;107: 1829-1835.
2. Meller D, Pires RT, Mack RJ, et al. Amniotic membrane transplantation for acute chemical or thermal burns. Ophthalmology 2000;107: 980-989.

3. Ishizaki M, Zhu G, Haseba T, et al. Expression of collagen I, smooth muscle $\alpha$-actin, and vimentin during the healing of alkali-burned and lacerated corneas. Invest Ophthalmol Vis Sci 1993;34:3320-3328.

4. Saika S, Kobata S, Hashizume N, et al. Epithelial basement membrane in alkali-burned corneas in rats. Immunohistochemical study. Cornea 1993;12:383-390.

5. Tomasek JJ, Gabbiani G, Hinz B, et al. Myofibroblasts and mechanoregulation of connective tissue remodelling. Nat Rev Mol Cell Biol 2002;3:349-363.

6. Saika S, Ikeda K, Yamanaka O, et al. Expression of Smad7 in mouse eyes accelerates healing of corneal tissue after exposure to alkali. Am J Pathol 2005;166:1405-1418.

7. Saika S, Miyamoto T, Yamanaka O, et al. Therapeutic effect of topical administration of SN50, an inhibitor of nuclear factor-kappaB, in treatment of corneal alkali burns in mice. Am J Pathol 2005;166: 1393-1403.

8. Saika S. TGF $\beta$ pathobiology in the eye. Lab Invest 2006;86:106-115.

9. Chiquet-Ehrismann R. Tenascins. Int J Biochem Cell Biol 2004;36: 986-990.

10. Tucker RP, Chiquet-Ehrismann R. The regulation of tenascin expression by tissue microenvironments. Biochim Biophys Acta 2008;1793: 888-992.

11. Midwood KS, Orend $G$. The role of tenascin- $C$ in tissue injury and tumorigenesis. J Cell Commun Signal 2009;3:287-310.

12. Shrestha $P$, Sakamoto $F$, Takagi $H$, et al. Enhanced tenascin immunoreactivity in leukoplakia and squamous cell carcinoma of the oral cavity: an immunohistochemical study. Eur J Cancer B Oral Oncol 1994;30:132-137.

13. El-Karef A, Yoshida T, Gabazza EC, et al. Deficiency of tenascin-C attenuates liver fibrosis in immune-mediated chronic hepatitis in mice. J Pathol 2007;211:86-94.

14. Maseruka $\mathrm{H}$, Bonshek RE, Tullo AB. Tenascin- $\mathrm{C}$ expression in normal, inflamed, and scarred human corneas. $\mathrm{Br} J$ Ophthalmol 1997;81: 677-682.

15. Maseruka H, Ridgway A, Tullo A, et al. Developmental changes in patterns of expression of tenascin- $C$ variants in the human cornea. Invest Ophthalmol Vis Sci 2000;41:4101-4107.

16. Matsuda A, Yoshiki A, Tagawa $Y$, et al. Corneal wound healing in tenascin knockout mouse. Invest Ophthalmol Vis Sci 1999;40: 1071-1080.

17. Saika S, Ikeda K, Yamanaka $\mathrm{O}$, et al. Loss of tumor necrosis factor a potentiates transforming growth factor $\beta$-mediated pathogenic tissue response during wound healing. Am J Pathol 2006;168:1848-1860.

18. Saika S, Ikeda K, Yamanaka O, et al. Adenoviral gene transfer of BMP-7, Id2, or Id3 suppresses injury-induced epithelial-to-mesenchymal transition of lens epithelium in mice. Am J Physiol Cell Physiol 2006; 290:282-289.

19. Fattman CL, Gambelli F, Hoyle G, et al. Epithelial expression of TIMP-1 does not alter sensitivity to bleomycin-induced lung injury in C57BL/6 mice. Am J Physiol Lung Cell Mol Physiol 2008;294:L572-L581.

20. Saika S, Yamanaka O, Sumioka T, et al. Fibrotic disorders in the eye: targets of gene therapy. Prog Retin Eye Res 2008;27:177-196.

21. Sumioka T, Fujita N, Kitano A, et al. Impaired angiogenic response in the cornea of mice lacking tenascin C. Invest Ophthalmol Vis Sci 2011;52:2462-2467.

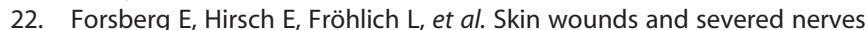
heal normally in mice lacking tenascin-C. Proc Natl Acad Sci USA 1996;93:6594-6599.

23. Sta Iglesia DD, Gala PH, Qiu T, et al. Integrin expression during epithelial migration and restratification in the tenascin-C-deficient mouse cornea. J Histochem Cytochem 2000;48:363-376.

24. Miyazaki K, Okada Y, Yamanaka O, et al. Corneal wound healing in an osteopontin-deficient mouse. Invest Ophthalmol Vis Sci 2008;49: 1367-1375.

25. Fujita N, Fujita S, Okada Y, et al. Impaired angiogenic response in the corneas of mice lacking osteopontin. Invest Ophthalmol Vis Sci 2010;51:790-794.

26. Ballard VL, Sharma A, Duignan I, et al. Vascular tenascin-C regulates cardiac endothelial phenotype and neovascularization. FASEB J 2006;20:717-719. 
27. Ishiwata $T$, Takahashi $K$, Shimanuki $Y$, et al. Serum tenascin- $C$ as a potential predictive marker of angiogenesis in non-small cell lung cancer. Anticancer Res 2005;25:489-495.

28. Saito $Y$, Shiota $Y$, Nishisaka $M$, et al. Inhibition of angiogenesis by a tenascin-c peptide which is capable of activating $\beta 1$-integrins. Biol Pharm Bull 2008;31:1003-1007.

29. Wallner K, Li C, Shah PK, et al. Tenascin-C is expressed in macrophagerich human coronary atherosclerotic plaque. Circulation 1999;99: 1284-1289.

30. Carey WA, Taylor GD, Dean WB, et al. Tenascin-C deficiency attenuates TGF- $\beta$-mediated fibrosis following murine lung injury. Am J Physiol Lung Cell Mol Physiol 2010;299:L785-L793.

31. Garamszegi N, Garamszegi SP, Samavarchi-Tehrani $P$, et al. Extracellular matrix-induced transforming growth factor- $\beta$ receptor signaling dynamics. Oncogene 2010;29:2368-2380.

32. Margadant C, Sonnenberg A. Integrin-TGF- $\beta$ crosstalk in fibrosis, cancer and wound healing. EMBO Rep 2010;11:97-105.
33. Bhowmick NA, Zent $R$, Ghiassi $M$, et al. Integrin $\beta 1$ signaling is necessary for transforming growth factor- $\beta$ activation of p38MAPK and epithelial plasticity. J Biol Chem 2001;276:46707-46713.

34. Lamar JM, lyer V, DiPersio CM. Integrin $\alpha 3 \beta 1$ potentiates TGF $\beta$ mediated induction of MMP-9 in immortalized keratinocytes. J Invest Dermatol 2008;128:575-586.

35. Scaffidi AK, Petrovic N, Moodley YP, et al. $\alpha(v) \beta(3)$ Integrin interacts with the transforming growth factor $\beta$ (TGF $\beta$ ) type II receptor to potentiate the proliferative effects of TGF $\beta 1$ in living human lung fibroblasts. J Biol Chem 2004;279:37726-37733.

36. Galliher AJ, Schiemann WP. $\beta 3$ integrin and Src facilitate trans forming growth factor- $\beta$ mediated induction of epithelialmesenchymal transition in mammary epithelial cells. Breast Cancer 2006;8:R42.

37. Asano $\mathrm{Y}, \mathrm{Ihn} \mathrm{H}$, Yamane $\mathrm{K}$, et al. Increased expression of integrin $\alpha \mathrm{v} \beta 5$ induces the myofibroblastic differentiation of dermal fibroblasts. Am J Pathol 2006;168:499-510. 